\title{
Comparative genomic analysis of a Shiga toxin-producing Escherichia coli (STEC) 0145:H25 associated with a severe pediatric case of hemolytic uremic syndrome in Davidson County, Tennessee, US
}

\author{
Julio A. Guerra ${ }^{1 \dagger}$, Chengxian Zhang ${ }^{2 \dagger}$, Jonathan E. Bard ${ }^{3}$, Donald Yergeau ${ }^{3}$, Natasha Halasa ${ }^{2}$ and
} Oscar G. Gómez-Duarte ${ }^{1,2^{*}}$ (D)

\begin{abstract}
Background: Shiga toxin-producing E. coli (STECS) are foodborne pathogens associated with bloody diarrhea and hemolytic uremic syndrome (HUS). Although the STEC 0157 serogroup accounts for the highest number of infections, HUS-related complications and deaths, the STEC non-O157, as a group, accounts for a larger proportion of STEC infections and lower HUS cases. There is limited information available on how to recognize non-O157 serotypes associated with severe disease. The objectives of this study were to describe a patient with STEC non-O157 infection complicated with HUS and to conduct a comparative whole genome sequence (WGS) analysis among the patient's STEC clinical isolate and STEC 0157 and non-O157 strains.

Results: The STEC 0145:H25 strain EN11-0044-2 was isolated from a pediatric patient with diarrhea, HUS and severe neurologic and cardiorespiratory complications, who was enrolled in a previously reported case-control study of acute gastroenteritis conducted in Davidson County, Tennessee in 2013. The strain EN11-0044-2 genome sequence contained a chromosome and three plasmids. Two of the plasmids were similar to those present in 0145:H25 strains whereas the third unique plasmid EN11-0044-2_03 shared no similarity with other STEC plasmids, and it carried 23 genes of unknown function. Strain EN11-0044-2, compared with O145:H25 and O157 serogroup strains shared chromosome- and plasmidencoded virulence factors, including Shiga toxin, LEE type III secretion system, LEE effectors, SFP fimbriae, and additional toxins and colonization factors.
\end{abstract}

\footnotetext{
* Correspondence: oscargom@buffalo.edu

†Julio A. Guerra and Chengxian Zhang contributed equally to this work.

${ }^{1}$ International Enteric Vaccine Research Program, Division of Infectious

Diseases, Department of Pediatrics, University at Buffalo, The State University

of New York (SUNY), Jacobs School of Medicine and Biomedical Sciences,

875 Ellicott St. Office 6090, Buffalo, NY 14203, USA

${ }^{2}$ Division of Pediatric Infectious Diseases, Department of Pediatrics, Vanderbilt University School of Medicine, Nashville, TN, USA

Full list of author information is available at the end of the article
}

(c) The Author(s). 2020 Open Access This article is licensed under a Creative Commons Attribution 4.0 International License, which permits use, sharing, adaptation, distribution and reproduction in any medium or format, as long as you give appropriate credit to the original author(s) and the source, provide a link to the Creative Commons licence, and indicate if changes were made. The images or other third party material in this article are included in the article's Creative Commons licence, unless indicated otherwise in a credit line to the material. If material is not included in the article's Creative Commons licence and your intended use is not permitted by statutory regulation or exceeds the permitted use, you will need to obtain permission directly from the copyright holder. To view a copy of this licence, visit http://creativecommons.org/licenses/by/4.0/ The Creative Commons Public Domain Dedication waiver (http://creativecommons.org/publicdomain/zero/1.0/) applies to the data made available in this article, unless otherwise stated in a credit line to the data. 


\begin{abstract}
(Continued from previous page)
Conclusions: A STEC 0145:H25 strain EN11-0044-2 was isolated from a pediatric patient with severe disease, including HUS, in Davidson County, TN. Phylogenetic and comparison WGS analysis provided evidence that strain EN11-0044-2 closely resembles O145:H25, and confirmed an independent evolutionary path of STEC O145:H25 and O145:H28 serotypes. The strain EN11-0044-2 virulence make up was similar to other O145:H25 and O157 serogroups. It carried stx2 and the LEE pathogenicity island, and additional colonization factors and enterotoxin genes. A unique feature of strain EN11-0044-2 was the presence of plasmid pEN11-0044-2_03 carrying genes with functions to be determined. Further studies will be necessary to elucidate the role that newly acquired genes by $0145: \mathrm{H} 25$ strains play in pathogenesis, and to determine if they may serve as genetic markers of severe disease.
\end{abstract}

Keywords: STEC, Diarrhea, Children, Gastroenteritis, Hemolytic-uremic syndrome

\section{Background}

Shiga toxin-producing Escherichia coli (STEC), also known as Vero toxin-producing E. coli $[1,2]$, are defined as strains that express one or two bacteriophageencoded Shiga toxins Stx1 and Stx2 [3]. STECs, a cause diarrhea and hemolytic uremic syndrome (HUS) in children and adults worldwide, may present in the form of sporadic cases or outbreaks $[4,5]$. O157 is the most common serogroup associated with diarrhea and HUS in the US. Nevertheless, non-O157 STEC serogroups are surpassing the number O157 STECs infections and have the potential for large outbreaks [4-16]. Up to $52 \%$ of all STEC associated disease is due to non-O157 STEC, which corresponds to more than 37,000 illnesses annually in the US [17]. Although O157 serogroup leads to more severe disease, the increasing number of nonO157 infections is of public health concern, first, because it is difficult to discern among those associated with more severe disease and also because virulence markers for detection are currently unknown $[7,13,18]$.

There are over 400 non-O157 STEC serotypes, of which more than 100 are reported to cause gastrointestinal disease in humans $[8,9]$. Strains from serogroups O26, O45, O103, O111, O121, and O145, also known as the "big six", are most frequently associated with human illness [13, 19-21]. A relevant non-O157 STEC is the O104:H4 serotype which emerged from an enteroaggregative E. coli (EAEC) by acquiring a stx2 phage that caused a large outbreak bloody diarrhea in Europe in 2011 with a high rate of HUS and mortality [22].

STEC serogroup O145 has been associated with outbreaks of diarrhea and HUS worldwide [21, 23-28]. Among the main serotypes within this serogroup, O145:H28 is the most frequently detected, with outbreaks reported in the US [26, 29] and Belgium [25, 30]. Serotype O145:H25 is less frequently detected yet, a larger proportion of reported cases are associated with HUS, highlighting the clinical significance of this serotype [24, 27, 31, 32]. Despite the importance of this serotype, there is limited information on the evolutionary path and the genomic composition, including the traits associated with virulence and colonization of this serotype. Furthermore, data are missing regarding whether O145: $\mathrm{H} 25$ has a distinct evolutionary lineage compared with $\mathrm{O} 145: \mathrm{H} 28$ [32]. Robust genomics integrated with epidemiology information may answer key questions about the virulence profile, disease severity, epidemic risk assessment, and genetic origin of these poorly characterized strains.

The objectives of this study were to describe a case of acute gastroenteritis associated with HUS in a Tennessean child and to conduct a comparative analysis of the whole genome sequence of this STEC O145:H25 clinical isolate with previously reported STEC O145:H25 and other STEC genomes. The child was enrolled as a participant in a National Vaccine Surveillance Network (NVSN) study in Davidson County, TN [33]. This STEC O145:H25 strain was identified in 2013, 1 year after a US multistate outbreak of STEC O145:H25 in 2012, that resulted in 18 infections, 4 hospitalizations and one death [34]. This study compared the genomics of the STEC O145:H25 strain EN1I-0044-2 with previously reported O145:H25 [32], O145:H28 [35] and other important STEC serotypes.

\section{Results and discussion \\ Clinical presentation and course}

We isolated a STEC O145:H25 strain from a child with acute gastroenteritis complicated with HUS. A 30month-old previously healthy Hispanic female, fully immunized, developed a non-bloody, mucus-containing diarrhea 5 days prior to hospital admission. Two days prior to admission, she complained of abdominal pain, nausea and multiple episodes of vomiting. Despite oral hydration with electrolyte solution administered at home, her condition continued to worsen due to persistent diarrhea and vomiting. Patient was brought to an Emergency Department (ED) by her parents, where she was initially diagnosed with a viral illness, given sublingual ondansetron and discharged to home. The following day, the diarrhea and vomiting persisted, and she returned to the ED where intravenous fluids (IVF) were initiated. Complete blood cell count $(\mathrm{CBC})$ revealed a 
white blood cell count of $29,000 / \mu \mathrm{L}$, platelet count 220 , $000 / \mu \mathrm{L}$, and creatinine at $1.4 \mathrm{mg} / \mathrm{dl}$. On the next day, the $\mathrm{CBC}$ was abnormal with a platelet count of only 102 , $000 / \mu \mathrm{L}$ and creatinine increased to $2.4 \mathrm{mg} / \mathrm{dl}$. The patient was diagnosed with bloody diarrhea and hemolytic uremic syndrome (HUS), presumptively secondary to STEC diarrhea, and transferred to a tertiary care children's hospital in Nashville, TN.

Upon arrival to the hospital, the patient had nausea, vomiting, diarrhea and altered mental status. She was directly admitted to the pediatric intensive care unit (PICU) for diagnosis and management. She was intubated due to impending respiratory failure and was mechanical ventilated. She received IVF and required several packed red blood cell transfusions due to HUSassociated anemia. She tested negative for rotavirus and positive for STEC by stool culture and molecular testing. Neurological evaluation, confirmed by magnetic resonance imaging (MRI), revealed extensive basal ganglia and thalamic restricted diffusion consistent with ischemic injury likely associated with HUS. The EEG showed frequent subclinical unilateral occipital lobe seizures and she was started on anti-convulsant medications. Cardiology evaluation reported increasing tachycardia, narrow pulse pressure, and the echocardiogram revealed pericardial effusion with tamponade as well as bilateral pleural effusion. An emergent pericardial drain was placed as well as a pleural catheter to drain pericardial fluid and pleural fluid, respectively. She also received milrinone and nicardipine to improve left ventricular function. HUS-associated renal failure in the presence of cardiac insufficiency and pericardial and pleural extravascular fluid prompted initiation of hemodialysis management. Patient's clinical condition improved over the following 4 weeks after admission and she was discharged to home with instructions for outpatient follow up.

\section{General genomic features of STEC 0145:H25 strain EN1I- 0044-2}

Despite the epidemiological importance of O145:H25 serotype STECs, there is limited information on the evolutionary path and the genomic composition, including the traits associated with virulence and colonization. Only two complete genomes of two O145:H25 strains associated with HUS have been previously described, and only one study has performed comparative genomic analysis [32].

Initially, the E. coli strain EN1I-0044-2 obtained from patient's stool sample tested positive for both eae and stx 2 genes by polymerase chain reaction (PCR) and serotyping results reported O145:H25 [33]. The STEC O145: H25 strain EN1I-0044-2 was further evaluated by whole genome sequence analysis that revealed a $5276,111 \mathrm{bp}$ genome consisting of 5417 coding DNA sequences
(CDS), 22 rRNAs, 89 tRNAs and 54 sRNAs. The backbone chromosome consisted of 5149 CDS, interrupted by mobile genetics elements (MGEs), including prophage/prophage-like elements $(n=13)$, integrate elements $(n=8)$, and insertion sequences $(n=62)$. The stx2 gene encoding Shiga toxin-2 was located in a prophage of about $31.8 \mathrm{~Kb}$ in size. The LEE pathogenicity island locus was integrated at the tRNA pheU locus. The STEC O145:H25 strain EN1I-0044-2 carries three plasmids, the pEHEC-like plasmid pEN1I0044-2_01 (49,096 bp) and two additional plasmids pEN1I-0044-2_02 (31,963 bp) and pEN1I-0044-2_03 (63,546 bp) (Table 1$)$.

In silico serotyping analysis confirmed that STEC strain EN1I-0044-2 belong to serotype O145:H25. Multilocus sequencing typing (MLST) showed that STEC strain EN1I-0044-2 belong to sequence type (ST) 5309. In contrast, STEC O145:H25 strain CFSAN004177 belong to ST 7061 (Table 2). Only $m d h$ allele was dissimilar among O145:H25 strains, differing in a single nucleotide polymorphism (SNP) (A431G). The WGS of reference STEC strains, showed significant conservation of the chromosomal backbone among STEC strains (Fig. 1). However, differences in the number and size of acquired MGEs such as prophages, IEs, and plasmids were identified among O145:H25 strains in comparison with other STEC strains (Table 1). Previously reported non-homologous regions, detected in O145:H25 strain CFSAN004177 and evaluated in strain EN1I-0044-2 [32] using Blast analysis, showed that these regions are present or partially present in strain EN1I-0044-2 (Additional file 1: Table S1).

\section{Phylogenetic analyses demonstrated clustering of 0145:H25 strains, including EN1I-0044-2}

In this study, phylogenetic analysis indicated that STEC O145:H25 strain EN1I-0044-2 has a common evolutionary lineage with two recently described O145:H25 strains, and a different evolutionary lineage from STEC O145:H28 strains which has been previously reported [32]. The maximum-likelihood tree constructed showed that strain EN1I-0044-2 was clustered with other O145: H25 strains. STEC O165:H25 strain 2012C-4227 was clustered with other O145:H25 strains. S. sonnei strain Ss046 was also clustered with $\mathrm{O} 145: \mathrm{H} 25$ and $\mathrm{O} 165: \mathrm{H} 25$ strains. In contrast, O145:H28 strains were distant from O145:H25 strains, and were clustered with S. dysenteriae strain Sd197, some STEC O157:H7 and EPEC O55: H7 strains. O145:H25 strains were also distant from important non-O157 STEC strains, including O103:H2 strain 12,009, O26:H11 strain 11,368, O111:HNM strain 11,128 and the German outbreak O104:H4 strain 2011C_3493 (Fig. 2). 
Table 1 Genome characteristics of STEC EN11-0044-2 compared with other highly pathogenic STECs

\begin{tabular}{|c|c|c|c|c|c|c|c|}
\hline Chromosome & $\begin{array}{l}\text { O145:H25 str. } \\
\text { EN1I-0044-2 }\end{array}$ & $\begin{array}{l}\text { O145:H25 str. } \\
\text { CFSAN004177 }\end{array}$ & $\begin{array}{l}\text { O145:H28 str. } \\
\text { RM13514 }\end{array}$ & $\begin{array}{l}\mathrm{O} 26: \mathrm{H} 11 \\
\text { str. 11,368 }\end{array}$ & $\begin{array}{l}\text { O103:H2 } \\
\text { str. 12,009 }\end{array}$ & $\begin{array}{l}\text { O111: H- } \\
\text { str. 11,128 }\end{array}$ & $\begin{array}{l}\text { O157:H7 } \\
\text { str. Sakai }\end{array}$ \\
\hline Size (kb) & 5131 & 5191 & 5586 & 5697 & 5449 & 5371 & 5498 \\
\hline GC (\%) & 50.5 & 50.5 & 50.7 & 50.7 & 50.7 & 50.6 & 50.5 \\
\hline CDSs & 5149 & 5193 & 5613 & 5364 & 5054 & 4972 & 5230 \\
\hline tRNA & 99 & 96 & 104 & 101 & 98 & 107 & 105 \\
\hline Prophages & 13 & 14 & 20 & 21 & 15 & 17 & 18 \\
\hline stx genes & $s t \times 2 a$ & $s t \times 2 a$ & $s t \times 2 a$ & $s t \times 1$ & $s t \times 1+2 a$ & $s t \times 1+2 a$ & $s t \times 1+2 a$ \\
\hline Number of $I^{a}$ & 55 & 73 & 53 & 62 & 50 & 56 & 37 \\
\hline Integrate elements (IE) & 8 & 9 & 7 & 9 & 6 & 7 & 6 \\
\hline LEE-island integration locus & pheU & phel & selc & pheU & pheV & pheV & selc \\
\hline \multicolumn{8}{|l|}{ pEHEC-like plasmid } \\
\hline Size (kb) & 50 & 52 & 87 & 85 & 76 & 78 & 93 \\
\hline GC (\%) & 47 & 47 & 47.6 & 47.5 & 49.1 & 50 & 47.6 \\
\hline CDSs & 79 & 58 & 94 & 98 & 67 & 72 & 85 \\
\hline Number of $I^{a}$ & 4 & 4 & 4 & 6 & 6 & 8 & 3 \\
\hline \multicolumn{8}{|l|}{ Other plasmid(s) } \\
\hline Size (kb) & $32 / 63$ & $35 / 96$ & 65 & $63 / 6 / 4$ & N/A & 205/98/8/7 & 3 \\
\hline GC (\%) & $49 / 51$ & $49 / 48$ & 53 & $52 / 46 / 44$ & N/A & $47 / 48 / 50 / 50$ & 43 \\
\hline CDSs & $48 / 86$ & $46 / 120$ & 69 & $93 / 10 / 3$ & N/A & $222 / 121 / 10 / 10$ & 3 \\
\hline Number of $I^{a}$ & $4 / 0$ & $5 / 0$ & 6 & $1 / 0 / 0$ & $\mathrm{~N} / \mathrm{A}$ & $14 / 1 / 0 / 0$ & 0 \\
\hline Total genome size (bp) & 5276 & 5374 & 5738 & 5855 & 5525 & 5767 & 5594 \\
\hline
\end{tabular}

${ }^{a}$ Insertion sequences (coverage $\geq 90 \%$, identity $\geq 90 \%$ )

\section{Mobile genetic elements identified in STEC 0145: $\mathrm{H} 25$ strain EN11-0044-2}

Comparative genomic analysis of STEC O145:H25 strain EN1I-0044-2 against the chromosome sequence of reference STEC strains revealed that there was significant conservation of the chromosomal backbone among STEC strains, as previously described [32, 35, 37, 39]. Similarities in the number and size of acquired MGEs such as plasmids, prophages, IEs, and IS were identified between strain EN1I-0044-2 and the other two STEC O145:H25 strains. However, dissimilarities of acquired MGEs were found between $\mathrm{O} 145: \mathrm{H} 25$ strains and other important STEC serotypes, which may explain the differences in the genome size among STEC strains [32]. Acquired MGEs are known to play an important role in driving genome and virulence evolution of STEC strains [35].

\section{Plasmids}

Previous studies have demonstrated that STEC strains differs considerably in the number and composition of plasmids [32, 35, 37] yet, O145:H25 strain EN1I-0044-2 carry two plasmids that are similar to other O145:H25

Table 2 MLST analysis of the STEC strains

\begin{tabular}{|c|c|c|c|c|c|c|c|c|c|c|}
\hline \multirow[t]{2}{*}{ Serotype } & \multirow[t]{2}{*}{ strain } & \multicolumn{7}{|c|}{ Seven $\boldsymbol{E}$. coli MLST gene loci allele profile } & \multirow[t]{2}{*}{ ST } & \multirow[t]{2}{*}{ ST Cplx } \\
\hline & & $a d k$ & fumC & gyrB & icd & $m d h$ & purA & $\operatorname{rec} A$ & & \\
\hline $\mathrm{O} 145: \mathrm{H} 25$ & EN11-0044-2a & 437 & 46 & 69 & 1 & $20^{\mathrm{b}}$ & 34 & 50 & 5309 & none \\
\hline $\mathrm{O} 145: \mathrm{H} 25$ & CFSAN004176 & 437 & 46 & 69 & 1 & 600 & 34 & 50 & 7061 & none \\
\hline $\mathrm{O} 145: \mathrm{H} 25$ & CFSAN004177 & 437 & 46 & 69 & 1 & 600 & 34 & 50 & 7061 & none \\
\hline $\mathrm{O} 145: \mathrm{H} 28$ & RM13514 & 19 & 23 & 18 & 24 & 21 & 2 & 16 & 32 & 32 \\
\hline $\mathrm{O} 26: \mathrm{H} 11$ & 11,368 & 16 & 4 & 12 & 16 & 9 & 7 & 7 & 21 & 29 \\
\hline O111:HNM & 11,128 & 6 & 4 & 12 & 16 & 9 & 7 & 12 & 16 & 29 \\
\hline O103:H2 & 12,009 & 6 & 4 & 3 & 17 & 7 & 7 & 6 & 17 & 20 \\
\hline O157:H7 & Sakai & 12 & 12 & 8 & 12 & 15 & 2 & 2 & 11 & 11 \\
\hline
\end{tabular}

a Study strain: STEC 0145:H25 strain EN1I-0044-2. ${ }^{\mathrm{b}}$ The $m d h$ allele was dissimilar among O145:H25 strains in a single nucleotide polymorphism (SNP). The SNP in strain EN11-0044-2 is A431G 


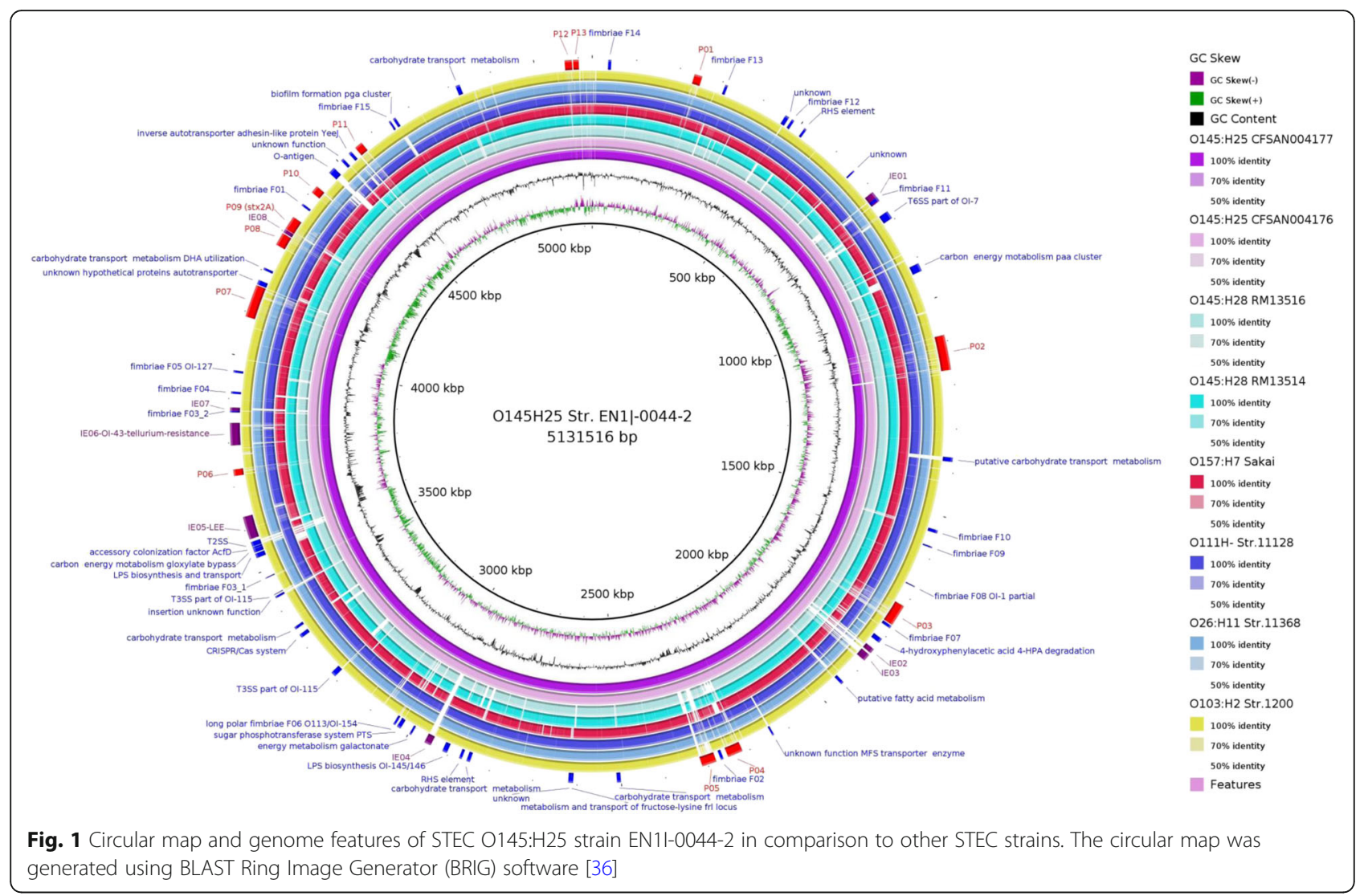

strains [32]. Subsequent DNA sequence analysis showed that the main pEN1I-0044-2_01 plasmid (49,096 bp) present in strain EN1I-0044-2 is similar to pEHEC-like virulence plasmids carried by others $\mathrm{O} 145: \mathrm{H} 25$ strains, including the virulence gene composition (99\% sequence identity with $98 \%$ sequence coverage). The second plasmid pEN1I-0044-2_02 is similar to pCFSAN004176P_01 [CP012492.1] and pCFSAN004177P_01 [CP012496.1] present in O145:H25 strains CFSAN004176 and CFSA N004177 (99\% sequence identity with 99 and 100\% sequence coverage, respectively). This plasmid carries the $s f p$ fimbrial gene cluster [32] which is also present among STEC O157 and O165 strain plasmids [40, 41].

The third plasmid pEN1I-0044-2_03 (63,546 bp) seems to be unique to STEC strain EN1I-0044-2 as it did not share homology with any of the additional plasmids present among STEC strains, including the two O145: H25 strains. In fact, pEN1I-0044-2_03 is similar to plasmids pM110_FII DNA [AP018140.1] from $E$. coli clinical isolate M110 isolated from blood specimen in a tertiary care hospital in Yangon, Myanmar [42] and pEC974-3 [CP021843.1] from E. coli clinical isolate EC974 from a women with urinary tract infection (UTI) [43]. However, pEN1I-0044-2_03 does not harbor resistance genes against quinolones and tetracycline present in pM110 FII DNA [42] or the DNA segment containing the class
A broad-spectrum beta-lactamase TEM-1 gene and IS elements/transposase genes such as IS1, IS6 and Tn3 family transposase harboring by pEC974-3 [43]. pEN1I-0044-2 03 , an IncF conjugative plasmid carries genes encoding conjugative transfer proteins and, in addition, it carries 23 genes of unknown function that deserved to be analyzed at the molecular level to discern their possible role in pathogenesis (Additional file 1, Table S4). Further studies will be necessary to determine if virulence phenotypes are associated to these plasmid-encoded genes. The sequence of this plasmid was annotated using RAST webserver (https://rast.nmpdr.org) [44-46].

\section{Prophages and integrate elements (IE)}

STEC strain EN1I-0044-2 has similar number and type of prophage/prophage-like elements to other O145:H25 strains [32]. STEC O145:H25 strain EN1I-0044-2 has 13 prophage/prophage-like elements and lambda-like phages were predominant among them (Table 3). The lambdalike family Stx2a phage in strain EN1I-0044-2 $(31.8 \mathrm{~kb})$ was smaller than Stx2a phages carried by $0145: \mathrm{H} 25$ strains CFSAN004176 (44.7 kb) and CFSAN004177 (44.7 $\mathrm{kb}$ ) (Additional file 6: Figure S1, panel A). The missing DNA region of phage Stx2a in strain EN1I-0044-2 carries 11 ORFs genes most of which encode phage-related proteins (Additional file 6: Figure S1, panel A). Comparison 


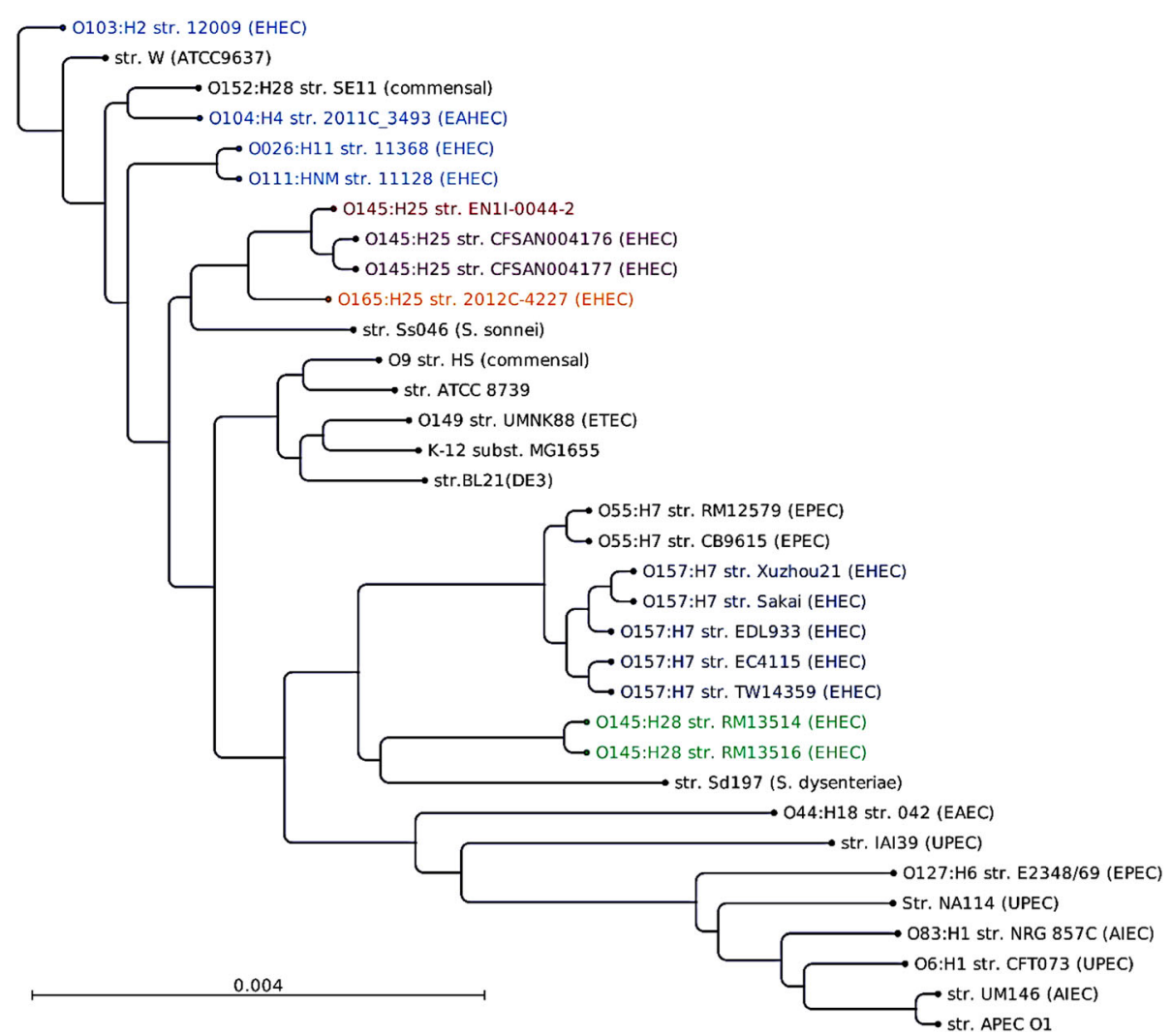

Fig. 2 Genome-wide phylogenetic analysis of E. coli and Shigella strains. The maximum likelihood (ML)-based phylogenetic tree based on the concatenated nucleotide sequences of 341 orthologous CDSs was constructed as described previously [35, 37]. Pairwise comparisons of all genome sequences were carried out using NUCmer from the MUMer package [38] and highly similar regions (repeated sequences) were removed from the analysis. Genomes were downloaded from GenBank, including 13 STEC strains, the German outbreak EHAEC strain, 17 other E. coli and 2 Shigella strains

and phylogenetic analysis showed that the Stx2a phage of strain EN1I-0044-2 was highly related to O145:H25 phages and unrelated to $\mathrm{O} 145: \mathrm{H} 28, \mathrm{O} 157, \mathrm{O} 111$, and O103 phages (Additional file 6: Figure S1, panel B).

STEC strain EN1I-0044-2 has 8 IE, two of them EI3 and EI4 carrying restriction-modification (RM) systems (phage defense mechanism) (Table 3), which have been described among EI of other STEC O145:H25 strains [32]. RM system was identified by the detection of methyltransferase (MTase) and restriction endonuclease (REase) genes by BLASTN comparison with other STEC O145:H25 strains. In addition, IE4 also carries a phage defense mechanism called Abortive infection (Abi) system. Abi is activated once a phage, evading restriction by host RM systems and by CRISPR, enters the host cell, leading to self-death ("suicide") to prevent spreading of phages to other cells [47].

\section{Non-homologous regions}

In contrast to prophages and IEs, which encode integrases that catalyze their excision and integration [48], non-homologous regions do not contain integrases or transposon genes. BLAST analysis of these regions previously detected in STEC O145:H25 strains [32] showed that all of them are present and/or partially present in strain EN1I-0044-2 (Additional file 1: Table S1). Dissimilarities among these regions has been previously detected in O145:H25 and other STEC strains [32]. These regions contain gene clusters associated with type II secretion system (T2SS), type VI secretion system (T6SS), CRISPR (clustered regularly interspersed palindromic repeats) loci, metabolism and fimbrial biosynthesis.

\section{Insertion sequences (IS)}

IS elements identified in strain EN1I-0044-2 were similar to those present in STEC O145:H25 strains and different from other STEC. The small differences in the distribution of IS elements among O145:H25 strains may be explained by differences at insertion sites since most of them are located in MGEs such as prophages, prophages like elements, IEs and plasmids. In fact, significant differences in the types and copy number of IS elements has been described among STEC strains [32, 49]. It's believed that IS elements not only play important roles in 
Table 3 Identified prophages and integrative elements (IE) in STEC 0145:H25 str. EN1I-0044-2

\begin{tabular}{|c|c|c|c|c|c|c|c|c|}
\hline Name & Contig & $\begin{array}{l}\text { Contig position } \\
\text { (start) }\end{array}$ & $\begin{array}{l}\text { Contig position } \\
\text { (end) }\end{array}$ & Size (Kb) & GC\% & Insertion site & Most common Phage Type & T3SS effector proteins \\
\hline \multicolumn{9}{|c|}{ Prophages } \\
\hline P01 & 1 & 234,098 & 252,152 & 22.3 & 48 & ybhB & $\begin{array}{l}\text { Stx2 converting phage } \\
\text { vB_EcoP_24B (Podoviridae-like) }\end{array}$ & traR, nleG, espJ \\
\hline P02 & 2 & 277,808 & 366,514 & 88.7 & 50.1 & ybhB & $\begin{array}{l}\text { Enterobacteria phage } \\
\text { YYZ-2008 (unclassified) }\end{array}$ & tRNA's (Arg, Met), nleG \\
\hline P03 & 3 & 254,241 & 303,995 & 49.8 & 49 & $y j b N$ & $\begin{array}{l}\text { Enterobacteria phage } \\
\text { mEp460 (lambda-like) }\end{array}$ & fos $A$ \\
\hline P04 & 4 & 202,949 & 238,006 & 35.1 & 52.4 & yhdJ & $\begin{array}{l}1 \text { Enterobacteria phage } \\
\text { P88 (Myoviridae) }\end{array}$ & \\
\hline P05 & 4 & 266,538 & 299,976 & 33.4 & 45 & tRNA (argW) & $\begin{array}{l}2 \text { Salmonella Phage } \\
\text { 103203_sal5 (Podoviridae) }\end{array}$ & \\
\hline P06 & 7 & 249,027 & 263,648 & 14.6 & 48.1 & $y j b N$ & $\begin{array}{l}3 \text { Enterobacteria phage } \\
\text { mEp460 (lambda-like) }\end{array}$ & \\
\hline P07 & 9 & 307 & 75,279 & 75 & 51.2 & tRNA (serU) & $\begin{array}{l}\text { Enterobacteria phage } \\
\text { lambda NC_001416 } \\
\text { (lambda-like) }\end{array}$ & traR, hydrolas \\
\hline P08 & 9 & 177,135 & 206,738 & 29.6 & 53.5 & ompW & $\begin{array}{l}\text { Enterobacteria phage } \\
\text { BP-4795 (lambda-like) }\end{array}$ & $\begin{array}{l}\text { terB, tRNA's (Met, Arg), } \\
\text { colonization factor AcfC }\end{array}$ \\
\hline P09 & 9 & 218,608 & 250,415 & 31.8 & 51 & yciE & $\begin{array}{l}\text { Enterobacteria phage } \\
\text { phiP27 (lambda-like) }\end{array}$ & $\begin{array}{l}\text { lom, peptidase S14, } \mathbf{s t} \times \mathbf{2} \boldsymbol{a}, \\
\text { serine protease }\end{array}$ \\
\hline P10 & 10 & 69,262 & 87,022 & 17.7 & 43.6 & yegl & $\begin{array}{l}\text { Enterobacteria phage } \\
\text { BP-4795 (lambda-like) }\end{array}$ & nleH, espJ, cif* \\
\hline P11 & 11 & 1 & 18,207 & 18.2 & 48.7 & & $\begin{array}{l}\text { Enterobacteria phage } \\
\text { mEp237 (lambda-like) }\end{array}$ & $\operatorname{ter} B$ \\
\hline P12 & 19 & 402 & 16,927 & 16.5 & 48.9 & ompW & Phage Gifsy-2 (unclassified) & tRNA's (Arg, Met) \\
\hline P13 & 20 & 2665 & 15,249 & 12.5 & 56.7 & & $\begin{array}{l}\text { Enterobacteria phage } \\
\text { BP-4795 (lambda-like) }\end{array}$ & \\
\hline \multicolumn{9}{|c|}{ Integrative elements } \\
\hline IE01 & 1 & 721,994 & 747,268 & 25.2 & 48 & tRNA (thrW) & & $\begin{array}{l}\text { Intimin-like adhesin fdeC, } \\
\text { fimbrial operon }\end{array}$ \\
\hline IE02 & 3 & 372,461 & 383,975 & 11.5 & 47 & yjjG & & restriction endonuclease \\
\hline IEO3 & 3 & 388,759 & 405,824 & 17 & 48 & tRNA (leuX) & & RM system, peptidase S8 \\
\hline IE04 & 5 & 390,657 & 406,347 & 15.7 & 44 & tRNA (selC) & & $\begin{array}{l}\text { Putative two-component } \\
\text { abortive infection system } \\
\text { (Abi), RM system }\end{array}$ \\
\hline IE05 & 7 & 102,015 & 153,886 & 51.9 & 38 & tRNA (phel) & LEE insertion site & $\begin{array}{l}\text { espA, espB, espD, espF, espG, } \\
\text { espH, espL, espS, espZ, map, } \\
\text { tir, eae, adhesin efa1, nleE, } \\
\text { nleB }\end{array}$ \\
\hline IE06 & 8 & 1 & 51,161 & 51.1 & 49 & tRNA (metX) & Ol-43 insertion site & $\begin{array}{l}\text { Urease operon, tellurium } \\
\text { resistance, espl }\end{array}$ \\
\hline IE07 & 8 & 78,288 & 86,298 & 8 & 42 & viuB-fimD & & \\
\hline IE08 & 9 & 209,198 & 217,645 & 8.4 & 41 & & & $\begin{array}{l}\text { nleG, nleG, espo, nleF, nleH, } \\
\text { espM }\end{array}$ \\
\hline
\end{tabular}

bacterial genome evolution and diversification [37, 39], but also participate in the immobilization of MGEs, resulting in their fixation in the genome [39]. A total of 15 types of IS elements with a total of 62 copies producing significant alignment were identified in the chromosome and plasmids sequences of STEC strain EN1I0044-2. IS600 was the most prevalent IS in the chromosome of $\mathrm{O} 145: \mathrm{H} 25$ strains, in contrast to other STEC strains such as O145:H28 strain RM13514 and O26:H11 in which a few copies were detected, or not detected, including O103:H2 strain 12,009, O111: HNM strain 11,128 and O157:H7 strain Sakai. IS629 was absent in O145:H25 strains but it was commonly found in the chromosome of STEC O157:H7 strain Sakai and 
non-O157 strains (Additional file 2: Table S1). In pEN1I-0044-2_01 and other pEHEC-like plasmids a few copies of IS were detected with no prevalence of a particular one. Secondary plasmid pEN1I-0044-2_02 carry four IS while pEN1I-0044-2_03 does not contain any IS (Additional file 2: Table S2).

\section{O-islands analysis}

A total of 177 genomic islands identified in O157:H7 strain EDL933 carry genes involved in metabolic, fitness and pathogenicity [50]. In this study, 47 of 177 (43\%) complete or partially present $\mathrm{O}$-islands were detected in O145:H25 strains EN1I-0044-2 (Additional file 1: Table S2). The LEE (OI-148) is similar in size and integration site to previously described $\mathrm{O} 145: \mathrm{H} 25$ strains, and the eae gene encoding intimin has the same size and subtype (beta) [32]. In contrast, LEE islands in O145:H28 strains are generally smaller in size and integrated at different tRNA, and carrying a different intimin type (gamma) $[32,35]$. In strain EN1I-0044-2, a partial OI-122 was found outside the LEE sequence. The OI-122 among $\mathrm{O} 145: \mathrm{H} 25$ strains contains the efa1 adhesin gene and three type III secretion system (T3SS) effector protein genes, and it is considered a LEE accessory region [32]. STEC O145:H25 strains carrying a second OI-122 related to T3SS is located outside the LEE island and partially conserved among STEC O145:H28 strains [35].

OI-7 (T6SS) and OI-115 (T3SS) are partially present in all three O145:H25 strains and others STEC strains. However, O145:H28 strains only have OI-115 [32, 35]. $\mathrm{O} 145: \mathrm{H} 25$ strains carries only OI-43 (including the urease gene cluster). In contrast, O145:H28 strain RM13514 carries both OI-43 and OI-48 and strain RM13516 only one (OI-43) [32, 35]. OI-43 and OI-48 (known as tellurian resistance islands) contain tellurian resistance and urease gene cluster [32, 35]. Urease has been suggested to play a role in cell acid resistance and in the gastrointestinal tract of the host $[35,51]$.

\section{Chromosomal and plasmid virulence factors identified}

The number of LEE and non-LEE encoded effectors present in strain EN1I-0044-2 is similar to other O145: $\mathrm{H} 25$ strains and it is different from other STEC serotypes [32]. LEE encodes a T3SS containing structural and effectors proteins. Among STEC serotypes O145: $\mathrm{H} 25, \mathrm{O} 26: \mathrm{H} 11$ and $\mathrm{O} 103: \mathrm{H} 2$, the EspA, B, and D proteins and the adhesin intimin receptor Tir are subtype $\beta$, while O145:H28 and O157:H7 are subtype $\gamma$. Non-LEEencoded effectors presented a similar pattern in O145: $\mathrm{H} 25$, except in the number of copies of the nleG gene; There were only 3 copies in strain pEN1I-0044-2 instead of the 9 described in O145:H25 strain CFSAN004177 (Additional file 2: Table S3).
Plasmid-encoded virulence genes previously reported in others pEHEC-like plasmids were evaluated in pEN1I0044-2_01 [32, 52]. pEN1I-0044-2_01 carry ehxA, hlyA and sta 1 genes and, lacks of $c b a, c m a$ ecf-cluster, espP, toxB, katP and $s t c E$ and toxB virulence genes (Table 4). Specifically, $c b a$ and $c m a$ gene sequence were disrupted by IS in strain EN1I-0044-2. The ecf-cluster has been associated with bacterial persistence in the bovine gastrointestinal tract [32]. No antimicrobial resistance genes were detected in the pEN1I-0044-2_01 or the other two additional plasmids present in O145:H25 strain EN1I0044-2 (Table 4).

Chromosome-encoded virulence gene analysis showed that strain EN1I-0044-2 carries a $\beta$ type intimin. Besides LEE and non-LEE encoded effectors and intimin, we detected $E f a 1$ encoding gene, previously reported to mediate intestinal colonization in calves [53]. Long Polar fimbriae cluster [54] was also detected in our strain EN1I-0044-2 and the other two O145:H25 strains CFSA N004176 and CFSAN004177 [32]. EhaA is a novel autotransporter protein of STEC O157:H7 that contributes to adhesion and biofilm formation that was also detected in our strain [55]. The EspI gene, a member of the SPATE family [56], is partially present in the chromosome of strain EN1I-0044-2 (only covers $52.7 \%$ of the gene sequence) yet, a complete copy of the gene was found in the plasmid pEN1I-0044-2_01. Strain EN1I0044-2 lacked the iha and pagC genes sequences but carry the resistance genes: gad, involved in serum resistance [57]; bor, involved in acid resistance [58]; and $\operatorname{sod} C$, involved in defense against extracellular phagocytederived reactive oxygen species ( $\operatorname{sod} C$ encodes superoxide dismutase) [59]. Two copies of gad gene were found in EN1I-0044-2. (Table 4).

\section{Fimbriae gene cluster analysis}

Fimbriae facilitate the initial attachment of STEC to intestinal cells and subsequence colonization of the host gut. The genome of STEC O157:H7 strains contain 16 loci-encoding genes putatively involved in pili biosynthesis $[60,61]$. We identified that the number of fimbrial gene clusters in strain EN1I-0044-2 was the same in other O145:H25 strains, and similar to STEC O157 strains described previously described. $15 / 19$ (78.9\%) of the fimbrial gene clusters evaluated were present in strain EN1I-0044-2. Fourteen of them were detected in the chromosome sequence and one (Sfp fimbria) in plasmid pEN1I-0044-2_02. Fimbrial gene clusters F17 and F19 were absent in O145:H25 strain EN1I-0044-2 while F08 and F16 are partially present (Additional file 1: Table S3). This data suggests that the hypervirulence phenotype of the STEC O145:H25 strains may require fimbrial-dependent adherence, yet it may not depend on 
Table 4 Virulence genes in STEC 0145:H25 strain EN1I-0044-2

\begin{tabular}{|c|c|c|c|c|c|c|c|}
\hline & & \multicolumn{3}{|l|}{$\mathrm{O} 145: \mathrm{H} 25$} & \multicolumn{2}{|l|}{$\mathrm{O} 145: \mathrm{H} 28$} & \multirow{2}{*}{$\begin{array}{l}\text { O157 } \\
\text { Sakai }\end{array}$} \\
\hline & & EN1I-0044-2 & CFSAN004176 & CFSAN004177 & RM13514 & RM13516 & \\
\hline Virulence gene & Product & Copy (Type) & Copy (Type) & Copy (Type) & Copy (Type) & Copy (Type) & Copy (Type) \\
\hline \multicolumn{8}{|c|}{ Chromosome-encoded } \\
\hline bor & Bor protein & $1^{a}$ & 1 & 1 & 1 & 1 & 2 \\
\hline eae & Intimin $\beta$ type & $1(\beta)^{b}$ & $1(\beta)$ & $1(\beta)$ & $1(\gamma)$ & $1(\gamma)$ & $1(\gamma)$ \\
\hline efal & EHEC factor for adherence & 1 & 2 & 2 & $+/-$ & 1 & $+/-$ \\
\hline ehaA & Autotransporter protein & 1 & 1 & 1 & 1 & 1 & 1 \\
\hline espl & Serine protease autotransporter & $(1)^{c}$ & 1 & 1 & 1 & - & - \\
\hline gad & Serum resistance gene & 2 & 1 & 1 & 1 & - & 1 \\
\hline Ipf cluster & Long Polar fimbriae & 1 & 1 & 1 & 1 & 1 & 2 \\
\hline $\operatorname{sod}(C u / Z n)$ & Superoxide dismutase & 1 & 1 & 1 & 2 & 2 & 2 \\
\hline Stx2 genes & Shiga toxin 2 & 1 & 1 & 1 & 1 & 1 & $2(s t \times 1, s t \times 2)$ \\
\hline \multicolumn{8}{|c|}{ Plasmid-encoded } \\
\hline ehxA & Enterohemolysin & $1(\mathrm{E})$ & $1(\mathrm{E})$ & $1(\mathrm{E})$ & $1(\mathrm{C})$ & $1(\mathrm{C})$ & $1(\mathrm{~B})$ \\
\hline hlyA & Hemolysin A & 1 & - & - & 1 & 1 & 1 \\
\hline sfp cluster & SFP fimbria & 1 & 1 & 1 & - & - & $-^{d}$ \\
\hline stal & Stable enterotoxin STla & 1 & 1 & 1 & - & - & - \\
\hline espl & Serine protease autotransporter & 1 & 1 & 1 & - & - & - \\
\hline
\end{tabular}

additional adherence-mediating genes such tox $B$, iha, or ecf [32].

The higher severity of STEC infections observed among patients infected with non-O157 strain including O145: H25 serotype strains remains unclear. Clinical severity of STEC O157 strains may be the result of the virulence make up. STEC non-O157 strains with similar virulence make may explain the clinical severity of some of these non-O157 serotype. Our study strain shared a number of virulence gene with $\mathrm{O} 157$ and non-O157 strain (Table 4). Major virulence genes in common, included stx2, type III secretion LEE and LEE effector genes. Other genes of interest shared by O145 and O157 serogroup strains tested were bor, efa1, ehaA, gad, lpf cluster, sod, and ehxA. Gen present in the study strain, O145:H25 strains and absent in O145:H28 include sfp fimbrial cluster, sta1, and espI. The sfp finbrial cluster was detected in O157, O165, and $\mathrm{O} 156$ strains most of them isolated from patients who suffered HUS [40, 62]. Although more epidemiological studies may be necessary to establish the association between $s f p$ cluster and higher HUS risk, the presence of this cluster may have epidemiological relevance as a marker to recognize STEC strains with high virulence potential. The association $s f p$ and additional $\mathrm{O} 145: \mathrm{H} 45$ unique genes may open the way to the development of unique genetic markers for the identification of hypervirulent O145:H25 strains associated with severe disease and life-threatening complications.

\section{Conclusion}

We describe detailed genomic information of a STEC O145:H25 strain associated with bloody diarrhea and HUS in a child in Davidson County, TN in 2013. Whole genome sequencing analysis demonstrated that strain EN1I-0044-2 is related to previously described O145: H25 strains that were associated with HUS cases in the US in 2003 and 2004. Phylogenic analysis showed that strain EN1I-0044-2 belongs to the same lineage to O145: H25 strains CFSAN004176 and CFSAN004177 and support the hypothesis that this serotype evolved independently from serotype O145:H28. Comparative analysis of EN1I-0044-2 and the other two O145:H25 strains showed small differences in the number and topology of MGEs, including prophages, IS and plasmids. O145:H25 serotypes and $\mathrm{O} 157$ serogroup share important virulence genes in addition to stx2, among them LEE T3SS, LEE effectors, fimbrial genes, non-fimbrial colonization factors and enterotoxins. Strain EN1I-0044-2 carries also the $s f p$ fimbrial cluster, shared by $\mathrm{O} 157$ serogroup strains, and the pEN1I-0044-2_03 plasmid that contained a number of genes whose role in pathogenesis is yet to be determined. Further studies directed to elucidate the function of genes unique among O145:H25 strains may improve our understanding of the role these genes may play in the pathogenesis of STEC disease and its severity. Unique virulence genes among O145:H25 strains may lead to the development of genetic markers 
for the detection of non-O157 STECs, and specifically O145:H45 strains associated with life-threatening STEC infections.

\section{Methods}

Bacterial strain

STEC O145:H25 strain EN1I-0044-2 was used in this study. This strain was isolated from a 30 month-old Hispanic female previously healthy with bloody diarrhea in Davison County, Tennessee, USA, while conducting active gastroenteritis surveillance under the New Vaccine Surveillance Network (NVSN) study (July 1, 2012, to June 30, 2013). The isolate EN1I-0044-2 obtained from patient's stool sample was positive for both eae and stx2 genes by PCR and reported as serotype O145:H25 [33].

\section{Whole genome sequencing, assembly, and annotation}

The STEC O145:H25 strain EN1I-0044-2 was cultured overnight in Luria broth at $37^{\circ} \mathrm{C}$ and $200 \mathrm{rpm}$. Genomic DNA (gDNA) was isolated using GenElute Bacterial Genomic DNA Kit (Sigma-Aldrich) according to manufacturer's instructions. The EN1I-0044-2 strain genome was sequenced by BGI Americas Corporation (Cambridge, MA) and was processed for de novo assembly, and comparative analysis. The libraries were prepared for $500 \mathrm{bp}$ and $2 \mathrm{~kb}$ inserts paired-end sequencing on Illumina HiSeq 2000 sequencing platform. A total of 8,688,160 and 9,588, 868 reads were generated from $500 \mathrm{bp}$ and $2 \mathrm{~kb}$ libraries. Short reads were assembled into genome sequence using SOAPdenovo Version: 2.04 (http://sourceforge.net/projects/soapdenovo2/files/SOAPdenovo2/) [63]. The final assembly comprised 40 scaffolds composed of 64 contigs, resulting in a final assembly size of 5276,096 bp.

Genome annotation was conducted by the National Center for Biotechnology Information (NCBI) Prokaryotic Genome Annotation Pipeline (PGAAP) (http://www.ncbi. nlm.nih.gov/genome/annotation_prok/). This Whole Genome Shotgun project has been deposited at the NCBI GenBank under the accession numbers QQVX00000000 and PRJNA448001 (https://www.ncbi.nlm.nih.gov/bioproject/ PRJNA448001).

\section{Comparative analysis of STEC genomes}

The circular map for genome comparison of STEC strains EN1I-0044-2 was generated by BLAST Ring Image Generator (BRIG) software (http://sourceforge. net/projects/brig) using BRIG default settings [36]. The EN1I-0044-2 strain genome was set as reference and BLASTed against eight STEC genomes. The accession number of these strains are described in Additional file 3: Table S1. Non-homologous regions previously detected in O145:H25 CFSAN004177 strain (Location and size of each non-homologous region are described in Additional file 1: Table S1) [32] were first BLASTed by Basic Local
Alignment against strain EN1I-0044-2. Subsequently, these regions, as well as other dissimilarities identified by BRIG image, were manually examined by CLC Genomics Workbench 11.0.1 (CLC Bio, Qiagen, Aarhus, Denmark).

\section{Whole-genome based phylogenetic analysis}

The maximum-likelihood tree was constructed using the concatenated nucleotide sequences in FASTA format of 341 orthologous CDSs from E. coli subst. MG1655 [NC_ 000913] as reference (Additional file 4). To compare these sequences, our strain and 33 available genome sequences that were downloaded from genbank, were converted into searchable blast databases. The NC_000913 concatenated conserved fasta sequences were then compared to each database using blastn, extracting the top corresponding CDS for each WGS. These sequences were then aggregated for each strain, and compared using the MAFFT alignment tool. Subsequently, the maximum likelihood (ML)-based phylogenetic trees was built as described before [35, 37]. Pairwise comparisons of all genome sequences were carried out using NUCmer from the MUMer package [38] and highly similar regions (repeated sequences) were removed from the analysis. Genomes were downloaded from GenBank, including 13 STEC strains, the German outbreak EHAEC strain, 17 other E. coli and 2 Shigella strains, accession number for strains used are included in Additional file 3: Table S2. The concatenated nucleotide sequences of 341 orthologous CDSs from 34 strains genomes used are included in Additional file 5.

\section{MLST, serotyping, virulence factors and antimicrobial resistance by WGS analysis}

MLST confirmation was performed by using the WGS and compared with the merged alleles sequences of each genes from the University of Warwick website (http:// mlst.warwick.ac.uk/mlst/dbs/Ecoli). Allele comparison among STEC strains was performed by using DNA Dynamo sequence analysis software (Copyright $\odot$ BlueTractorSoftware Ltd). In silico serotyping for previously described $\mathrm{O}$ and $\mathrm{H}$ type genes was conducted by using whole-genome sequencing (WGS) data using the BLAST tool SerotypeFinder 1.1 [64]. Virulence Factors of Pathogenic Bacteria database (VFDB) [65] was used for virulence factors screening. In addition, we used VirulenceFinder 1.5; which contain the E. coli virulence gene database [66]. The identification of acquired antimicrobial resistance genes was performed using a ResFinder 3.0 [67]. SerotypeFinder 1.1, VirulenceFinder 1.5 and ResFinder 3.0 web servers can be access at Center for Genomic Epidemiology (CGE) database (http://www.genomicepidemiology.org/). 


\section{Plasmid identification}

Initial identification of plasmids in O145:H25 strain EN1I-0044-2 genome was achieved using the PlasmidFinder 1.3 tool available on the CGE webserver [68]. Nucleotide sequence of the identified contigs with high probability coming from plasmid were used for a BLAST search in NCBI website (https://blast.ncbi.nlm.nih.gov/ Blast.cgi). Progressive Mauve was used to generate alignment and perform comparison analysis with plasmids sequences producing significant alignments obtained from NCBI [69].

\section{Prophages, integrated elements and genomic island identification}

Initial identification and annotation of prophage sequences within O145:H25 strain EN1I-0044-2 genome was performed using PHASTER web server [70]. EIs such as genomic islands (GIs) were initially predicted by an integrated interface for computational identification and visualization of genomic islands "Islandviewer4" [71]. All prophages and EIs were examined manually for accuracy of the prediction using Mauve by locating integrases and potential integration sites [69] or by CLC Genomics Workbench 11.0.1 (CLC Bio, Qiagen, Aarhus, Denmark) (Table 3). Phylogenetic tree of the stx2a prophage of O145:H25 strain EN1I-0044-2 and other STEC strains was performed using by CLC Genomics Workbench 11.0.1 (CLC Bio, Qiagen, Aarhus, Denmark).

Genomic island detection was performed by BLAST analysis by using genomic islands sequences previously identified in STEC O157:H7 strains EDL933 (Additional file 1: Table S2) [50]. Fimbrial gene cluster were identified by BLAST analysis using the locus tag of each gene in each gene clusters present in O145:H25 strain CFSAN004176 and other STEC as previously described [32].

\section{Insertion sequence (IS) identification}

Initial IS elements identification and location was conducted using ISfinder webserver database [72]. Number of copies of each one of the identified IS elements were detected by nucleotide BLAST of the IS element and the genome of O145:H25 strain EN1I-0044-2 using Blastn suit from NCBI (https://blast.ncbi.nlm.nih.gov/Blast.cgi). Only highly similar sequences with $\geq 90 \%$ of coverage and $\geq 90 \%$ of identity to the identified IS elements were considered for the analysis. We used the same parameters to identify IS elements previously described for O145:H25 strains CFSAN004176 and CFSAN004177 [32]. IS elements identified either in our strain and the other two O145:H25 strains were used for comparative analysis (Additional file 2: Table S2).

\section{Supplementary information}

Supplementary information accompanies this paper at https://doi.org/10. 1186/s12864-020-06967-3.

Additional file 1: Table S1. Non-homologous region analysis. Table S2. O-islands analysis. Table S3. Fimbrial gene cluster analysis. Table S4. Sequence annotation of pEN1I-0044-2_03 plasmid by RAST.

Additional file 2: Table S1. Insertion sequence analysis. Table S2. LEEand non-LEE-encoded effectors analysis.

Additional file 3: Table S1. Strains used for comparative analysis. Table S2. Strains used for phylogenetic analysis.

Additional file 4: List of the 341 conserved CDSs from E. coli K-12 MG1655 strain.

Additional file 5. Concatenated nucleotide sequences of 341 orthologous CDSs from 34 bacterial strains.

Additional file 6: Figure S1. Stx2a prophages gene alignment and evolutionary relationships. Panel A, Diagram of gene alignment of Stx2a phage from STEC 0145:H25 CFASN004177 and phage P09 from study strain STEC 0145:H25 EN11-0044-2. Annotated sequence of Stx2a prophage from strain CFSAN004177 was taken from GenBank: [CP014670.1], position start: 4,500,642 and position end: 4,545,386. Prophage alignment was performed using Mauve (Darling AE, Mau B, Perna NT., 2010). Numbers indicate ORFs. Numbers in read correspond to virulence genes, among them the st×2A and B genes. Panel B, Phylogenetic tree of P09 phage sequence compared with stx2a prophages from $0145: \mathrm{H} 25$, O145:H28, O157, and additional non-0157 serogroups. The maximum likelihood (ML)-based phylogenetic tree based on phage sequence comparisons.

\section{Abbreviations}

STEC: Shiga toxin-producing Escherichia coli; EHEC: Enterohemorrhagic Escherichia coli; NVSN: National Vaccine Surveillance Network; HUS: Hemolytic uremic syndrome; LEE: Locus of enterocyte effacement; CDS: Coding DNA sequence; T3SS: Type III secretion system; MGEs: Mobile genetics elements; O-islands: Genomics islands

\section{Acknowledgements}

We are grateful to Dr. James D. Chappell for invaluable discussions on this study.

\section{Authors' contributions}

OGGD, JAG, DY conceived and designed the study. JAG, CZ and JEB performed the bioinformatics work. JAG, CZ and OGGD participate in the data analysis. JAG and OGGD wrote the manuscript. JAG, CZ, JEB, DY, NH, and OGGD participated in manuscript reviewing and editing. All authors read and approved the final manuscript.

\section{Funding}

This study was funded in part by funds from the Department of Pediatrics, Vanderbilt University School of Medicine and Department of Pediatrics, Jacobs School of Medicine and Biomedical Sciences, University at Buffalo, to O.G.G.-D.

\section{Availability of data and materials}

This Whole Genome Shotgun project for the STEC 0145:H25 strain EN1I-0044-2 has been deposited at the NCBI GenBank under the accession numbers QQVX00000000 and PRJNA448001 (https://www.ncbi.nlm.nih.gov/bioproject/ PRJNA448001).

All the other supporting data are included as additional files. Non-homologous regions are described in Additional file 1: Table S1. The accession number of strains used for the comparative analysis are included in Additional file 3: Table S1. The accession number of strains used for the whole-genome based phylogenetic analysis are included in Additional file 3: Table S2. The 341 non-recombinogenic CDSs from E. coli K-12 MG1655 strain used for phylogenetic analysis are included in Additional file 4. Concatenated nucleotide sequences of 341 orthologous CDSs from 34 strains used for phylogenetic analysis are included in Additional file 5. 


\section{Ethics approval and consent to participate}

The STEC strains analyzed in the present study was obtained under a prospective, cross-sectional active surveillance study enrolled children who were 15 days to 11 years old and who resided in Davidson County, Tennessee, presenting to the Vanderbilt Children's Hospital Emergency Department. This study was approved by the Vanderbilt University IRB and parents or guardians provided written informed consent for subject participation. This study was approved by the Vanderbilt University Institutional Review Board, No. 120099.

\section{Consent for publication}

Not Applicable.

\section{Competing interests}

The authors declare that they have no competing interests.

\section{Author details}

'International Enteric Vaccine Research Program, Division of Infectious Diseases, Department of Pediatrics, University at Buffalo, The State University of New York (SUNY), Jacobs School of Medicine and Biomedical Sciences, 875 Ellicott St. Office 6090, Buffalo, NY 14203, USA. ${ }^{2}$ Division of Pediatric Infectious Diseases, Department of Pediatrics, Vanderbilt University School of Medicine, Nashville, TN, USA. ${ }^{3}$ UB Genomics and Bioinformatics Core, Center of Excellence in Bioinformatics, University at Buffalo, The State University of New York, Buffalo, NY, USA.

\section{Received: 11 February 2020 Accepted: 3 August 2020} Published online: 17 August 2020

\section{References}

1. Nataro JP, Kaper JB. Diarrheagenic Escherichia coli. Clin Microbiol Rev. 1998; $11: 142$.

2. Karmali MA, Petric M, Lim C, Fleming PC, Arbus GS, Lior H. The association between idiopathic hemolytic uremic syndrome and infection by Verotoxinproducing Escherichia coli. J Infect Dis. 1985;151(5):775-82.

3. Melton-Celsa AR. Shiga toxin (Stx) classification, structure, and function. Microbiol Spectrum. 2014;2(4):37 Ehec-0024-2013.

4. Rangel JM, Sparling PH, Crowe C, Griffin PM, Swerdlow DL. Epidemiology of Escherichia coli 0157:H7 outbreaks, United States, 1982-2002. Emerg Infect Dis. 2005;11(4):603-9.

5. Manning SD, Motiwala AS, Springman AC, Qi W, Lacher DW, Ouellette LM, et al. Variation in virulence among clades of Escherichia coli 0157:H7 associated with disease outbreaks. Proc Natl Acad Sci U S A. 2008;105:4868.

6. Byrne L, Vanstone GL, Perry NT, Launders N, Adak GK, Godbole G, et al. Epidemiology and microbiology of Shiga toxin-producing Escherichia coli other than serogroup 0157 in England, 2009-2013. J Med Microbiol. 2014; 63(Pt 9):1181-8.

7. Centers for Disease C, (CDC) P. Vital signs: incidence and trends of infection with pathogens transmitted commonly through food--foodborne diseases active surveillance network, 10 U.S. sites, 1996-2010. MMWR Morb Mortal Wkly Rep. 2011;60(22):749 2011 Jun 10. Report No.: 1545-861X (Electronic) 0149-2195 (Linking) Contract No.: 22.

8. Johnson KE, Thorpe CM, Sears CL. The emerging clinical importance of nonO157 Shiga toxin-producing Escherichia coli. Clin Infect Dis. 2006:43:1587.

9. Bettelheim KA. The non-0157 Shiga-toxigenic (verocytotoxigenic) Escherichia coli; under-rated pathogens. Crit Rev Microbiol. 2007;33(1):67-87.

10. Rasko DA, Webster DR, Sahl JW, Bashir A, Boisen N, Scheutz F, et al. Origins of the E. coli strain causing an outbreak of hemolytic-uremic syndrome in Germany. N Engl J Med. 2011;365:709.

11. Gerber A, Karch H, Allerberger F, Verweyen HM, Zimmerhackl LB. Clinical course and the role of Shiga toxin-producing Escherichia coli infection in the hemolytic-uremic syndrome in pediatric patients, 1997-2000, in Germany and Austria: a prospective study. J Infect Dis. 2002;186(4):493-500.

12. Eklund M, Scheutz F, Siitonen A. Clinical isolates of non-O157 Shiga toxinproducing Escherichia coli: serotypes, virulence characteristics, and molecular profiles of strains of the same serotype. J Clin Microbiol. 2001;39(8):2829-34.

13. Brooks JT, Sowers EG, Wells JG, Greene KD, Griffin PM, Hoekstra RM, et al. Non-0157 Shiga toxin-producing Escherichia coli infections in the United States, 1983-2002. J Infect Dis. 2005;192:1422.

14. Hadler JL, Clogher P, Hurd S, Phan Q, Mandour M, Bemis K, et al. Ten-year trends and risk factors for non-O157 Shiga toxin-producing Escherichia coli found through Shiga toxin testing, Connecticut, 2000-2009. Clin Infect Dis. 2011;53(3):269-76.

15. Hale CR, Scallan E, Cronquist AB, Dunn J, Smith K, Robinson T, et al. Estimates of enteric illness attributable to contact with animals and their environments in the United States. Clin Infect Dis. 2012;54(suppl_5):S472-S9.

16. Luna-Gierke RE, Griffin PM, Gould LH, Herman K, Bopp CA, Strockbine N, et al. Outbreaks of non-0157 Shiga toxin-producing Escherichia coli infection: USA. Epidemiol Infect. 2014;142(11):2270-80.

17. Hedican EB, Medus C, Besser JM, Juni BA, Koziol B, Taylor C, et al. Characteristics of 0157 versus non-0157 Shiga toxin-producing Escherichia coli infections in Minnesota, 2000-2006. Clin Infect Dis. 2009;49(3):358-64.

18. Espie E, Grimont F, Mariani-Kurkdjian P, Bouvet P, Haeghebaert S, Filliol I, et al. Surveillance of hemolytic uremic syndrome in children less than 15 years of age, a system to monitor 0157 and non-0157 Shiga toxinproducing Escherichia coli infections in France, 1996-2006. Pediatr Infect Dis J. 2008;27(7):595-601.

19. Mathusa EC, Chen Y, Enache E, Hontz L. Non-O157 Shiga toxin-producing Escherichia coli in foods. J Food Prot. 2010;73:1721.

20. Hegde NV, Cote R, Jayarao BM, Muldoon M, Lindpaintner K, Kapur V, et al. Detection of the top six non-O157 Shiga toxin-producing Escherichia coli O groups by ELISA. Foodborne Pathog Dis. 2012;9:1044.

21. Valilis E, Ramsey A, Sidiq S, DuPont HL. Non-0157 Shiga toxin-producing Escherichia coli-a poorly appreciated enteric pathogen: systematic review. Int J Infect Dis. 2018;76:82-7.

22. Frank C, Werber D, Cramer JP, Askar M, Faber M. An der Heiden M, et al. epidemic profile of Shiga-toxin-producing Escherichia coli 0104:H4 outbreak in Germany. N Engl J Med. 2011;365(19):1771-80.

23. Rivero MA, Passucci JA, Rodriguez EM, Parma AE. Role and clinical course of verotoxigenic Escherichia coli infections in childhood acute diarrhoea in Argentina. J Med Microbiol. 2010;59(Pt 3):345-52.

24. Sonntag AK, Prager R, Bielaszewska M, Zhang W, Fruth A, Tschape H, et al. Phenotypic and genotypic analyses of enterohemorrhagic Escherichia coli O145 strains from patients in Germany. J Clin Microbiol. 2004;42(3):954-62.

25. De Schrijver K, Buvens G, Posse B, Van den Branden D, Oosterlynck O, De Zutter $\mathrm{L}$, et al. Outbreak of verocytotoxin-producing E. coli $\mathrm{O} 145$ and $\mathrm{O} 26$ infections associated with the consumption of ice cream produced at a farm, Belgium, 2007. Euro Surveill. 2008;13:1.

26. Taylor EV, Nguyen TA, Machesky KD, Koch E, Sotir MJ, Bohm SR, et al. Multistate outbreak of Escherichia coli 0145 infections associated with romaine lettuce consumption, 2010. J Food Prot. 2013;76:939.

27. Fierz L, Cernela N, Hauser E, Nüesch-Inderbinen M, Stephan R. Characteristics of Shigatoxin-producing Escherichia coli strains isolated during 2010-2014 from human infections in Switzerland. Front Microbiol. 2017;8(1471):1.

28. Carter MQ, Quinones B, He X, Zhong W, Louie JW, Lee BG, et al. An environmental Shiga toxin-producing Escherichia coli 0145 clonal population exhibits high-level phenotypic variation that includes virulence traits. Appl Environ Microbiol. 2016;82(4):1090-101.

29. Folster JP, Pecic G, Taylor E, Whichard J. Characterization of isolates from an outbreak of multidrug-resistant, Shiga toxin-producing Escherichia coli 0145 in the United States. Antimicrob Agents Chemother. 2011;55:5955.

30. Buvens G, Posse B, De Schrijver K, De Zutter L, Lauwers S, Pierard D. Virulence profiling and quantification of verocytotoxin-producing Escherichia coli $0145: \mathrm{H} 28$ and $026: \mathrm{H} 11$ isolated during an ice cream-related hemolytic uremic syndrome outbreak. Foodborne Pathog Dis. 2011;8:421.

31. Kuehne A, Bouwknegt M, Havelaar A, Gilsdorf A, Hoyer P, Stark K, et al. Estimating true incidence of 0157 and non-0157 Shiga toxin-producing Escherichia coli illness in Germany based on notification data of haemolytic uraemic syndrome. Epidemiol Infect. 2016;144(15):3305-15.

32. Lorenz SC, Gonzalez-Escalona N, Kotewicz ML, Fischer M, Kase JA. Genome sequencing and comparative genomics of enterohemorrhagic Escherichia coli 0145:H25 and 0145:H28 reveal distinct evolutionary paths and marked variations in traits associated with virulence \& colonization. BMC Microbiol. 2017;17(1):183.

33. Imdad A, Foster MA, lqbal J, Fonnesbeck C, Payne DC, Zhang C, et al. Diarrheagenic Escherichia coli and acute gastroenteritis in children in Davidson County, Tennessee, United States: a case-control study. Pediatr Infect Dis J. 2018;37(6):543-8.

34. (CDC) CfDCaP. Multistate outbreak of Shiga toxin-producing Escherichia coli O145 infections (final update); 2012.

35. Cooper KK, Mandrell RE, Louie JW, Korlach J, Clark TA, Parker CT, et al. Comparative genomics of enterohemorrhagic Escherichia coli O145:H28 
demonstrates a common evolutionary lineage with Escherichia coli O157: H7. BMC Genomics. 2014;15(1):17.

36. Alikhan NF, Petty NK, Ben Zakour NL, Beatson SA. BLAST ring image generator (BRIG): simple prokaryote genome comparisons. BMC Genomics. 2011;12:402.

37. Ogura $Y$, Ooka T, Iguchi A, Toh $H$, Asadulghani $M$, Oshima $K$, et al. Comparative genomics reveal the mechanism of the parallel evolution of O157 and non-0157 enterohemorrhagic Escherichia coli. Proc Natl Acad Sci U S A. 2009;106(42):17939-44.

38. Delcher AL, Kasif S, Fleischmann RD, Peterson J, White O, Salzberg SL. Alignment of whole genomes. Nucleic Acids Res. 1999;27(11):2369-76.

39. Ooka T, Ogura Y, Asadulghani M, Ohnishi M, Nakayama K, Terajima J, et al. Inference of the impact of insertion sequence (IS) elements on bacterial genome diversification through analysis of small-size structural polymorphisms in Escherichia coli 0157 genomes. Genome Res. 2009;19(10): 1809-16.

40. Bielaszewska M, Prager R, Vandivinit L, Musken A, Mellmann A, Holt NJ, et al. Detection and characterization of the fimbrial sfp cluster in enterohemorrhagic Escherichia coli 0165:H25/NM isolates from humans and cattle. Appl Environ Microbiol. 2009;75(1):64-71.

41. Musken A, Bielaszewska M, Greune L, Schweppe CH, Muthing J, Schmidt H, et al. Anaerobic conditions promote expression of Sfp fimbriae and adherence of sorbitol-fermenting enterohemorrhagic Escherichia coli 0157: NM to human intestinal epithelial cells. Appl Environ Microbiol. 2008;74(4): 1087-93.

42. Sugawara Y, Akeda Y, Sakamoto N, Takeuchi D, Motooka D, Nakamura S, et al. Genetic characterization of blaNDM-harboring plasmids in carbapenem-resistant Escherichia coli from Myanmar. PLoS One. 2017;12(9): e0184720.

43. Kao CY, Chen JW, Liu TL, Yan JJ, Wu JJ. Comparative genomics of Escherichia coli sequence type 219 clones from the same patient: evolution of the Incl1 blaCMY-carrying plasmid in vivo. Front Microbiol. 2018;9:1518.

44. Aziz RK, Bartels D, Best AA, DeJongh M, Disz T, Edwards RA, et al. The RAST server: rapid annotations using subsystems technology. BMC Genomics. 2008;9:75.

45. Overbeek R, Olson R, Pusch GD, Olsen GJ, Davis JJ, Disz T, et al. The SEED and the rapid annotation of microbial genomes using subsystems technology (RAST). Nucleic Acids Res. 2014;42(Database issue):D206-14.

46. Brettin T, Davis JJ, Disz T, Edwards RA, Gerdes S, Olsen GJ, et al. RASTtk: a modular and extensible implementation of the RAST algorithm for building custom annotation pipelines and annotating batches of genomes. Sci Rep. 2015:5:8365.

47. Stern A, Sorek R. The phage-host arms race: shaping the evolution of microbes. Bioessays. 2011;33(1):43-51.

48. Guédon G, Libante V, Coluzzi C, Payot S, Leblond-Bourget N. The obscure world of integrative and Mobilizable elements, highly widespread elements that pirate bacterial conjugative systems. Genes. 2017;8(11):337.

49. Cooper KK, Mandrell RE, Louie JW, Korlach J, Clark TA, Parker CT, et al. Complete genome sequences of two Escherichia coli O145:H28 outbreak strains of food origin. Genome Announc. 2014;2:3.

50. Perna NT, Plunkett G 3rd, Burland V, Mau B, Glasner JD, Rose DJ, et al. Genome sequence of enterohaemorrhagic Escherichia coli 0157:H7. Nature. 2001;409(6819):529-33.

51. Steyert SR, Kaper JB. Contribution of urease to colonization by Shiga toxinproducing Escherichia coli. Infect Immun. 2012;80:2589.

52. Lorenz SC, Monday SR, Hoffmann M, Fischer M, Kase JA. Plasmids from Shiga toxin-producing Escherichia coli strains with rare Enterohemolysin gene (ehxA) subtypes reveal pathogenicity potential and display a novel evolutionary path. Appl Environ Microbiol. 2016;82(21):6367-77.

53. Stevens MP, van Diemen PM, Frankel G, Phillips AD, Wallis TS. Efa1 influences colonization of the bovine intestine by Shiga toxin-producing Escherichia coli serotypes 05 and 0111. Infect Immun. 2002;70(9):5158-66.

54. Doughty S, Sloan J, Bennett-Wood V, Robertson M, Robins-Browne RM, Hartland EL. Identification of a novel fimbrial gene cluster related to long polar fimbriae in locus of enterocyte effacement-negative strains of enterohemorrhagic Escherichia coli. Infect Immun. 2002;70(12):6761-9.

55. Wells TJ, Sherlock O, Rivas L, Mahajan A, Beatson SA, Torpdahl M, et al. EhaA is a novel autotransporter protein of enterohemorrhagic Escherichia coli 0157:H7 that contributes to adhesion and biofilm formation. Environ Microbiol. 2008;10(3):589-604.
56. Weiss A, Kortemeier D, Brockmeyer J. Biochemical characterization of the SPATE members EspPalpha and Espl. Toxins (Basel). 2014;6(9):2719-31.

57. Barondess JJ, Beckwith J. Bor gene of phage lambda, involved in serum resistance, encodes a widely conserved outer membrane lipoprotein. J Bacteriol. 1995;177(5):1247-53.

58. Castanie-Cornet MP, Penfound TA, Smith D, Elliott JF, Foster JW. Control of acid resistance in Escherichia coli. J Bacteriol. 1999;181(11):3525-35.

59. De Groote MA, Ochsner UA, Shiloh MU, Nathan C, McCord JM, Dinauer MC, et al. Periplasmic superoxide dismutase protects salmonella from products of phagocyte NADPH-oxidase and nitric oxide synthase. Proc Natl Acad Sci U S A. 1997:94(25):13997-4001.

60. Rendon MA, Saldana Z, Erdem AL, Monteiro-Neto V, Vazquez A, Kaper JB, et al. Commensal and pathogenic Escherichia coli use a common pilus adherence factor for epithelial cell colonization. Proc Natl Acad Sci U S A. 2007;104(25):10637-42.

61. La Ragione RM, Best A, Woodward MJ, Wales AD. Escherichia coli O157:H7 colonization in small domestic ruminants. FEMS Microbiol Rev. 2009;33(2): 394-410.

62. Geue L, Schares S, Mintel B, Conraths FJ, Müller E, Ehricht R. Rapid microarray-based genotyping of enterohemorrhagic Escherichia coli serotype 0156: $\mathrm{H} 25 / \mathrm{H}-/ \mathrm{Hnt}$ isolates from cattle and clonal relationship analysis. Appl Environ Microbiol. 2010;76(16):5510-9.

63. Li R, Zhu H, Ruan J, Qian W, Fang X, Shi Z, et al. De novo assembly of human genomes with massively parallel short read sequencing. Genome Res. 2010;20(2):265-72.

64. Joensen KG, Tetzschner AM, Iguchi A, Aarestrup FM, Scheutz F. Rapid and easy in silico serotyping of Escherichia coli isolates by use of whole-genome sequencing data. J Clin Microbiol. 2015;53(8):2410-26.

65. Chen L, Zheng D, Liu B, Yang J, Jin Q. VFDB 2016: hierarchical and refined dataset for big data analysis--10 years on. Nucleic Acids Res. 2016;44(D1): D694-7.

66. Joensen KG, Scheutz F, Lund O, Hasman H, Kaas RS, Nielsen EM, et al. Realtime whole-genome sequencing for routine typing, surveillance, and outbreak detection of verotoxigenic Escherichia coli. J Clin Microbiol. 2014; 52(5):1501-10.

67. Zankari E, Hasman H, Cosentino S, Vestergaard M, Rasmussen S, Lund O, et al. Identification of acquired antimicrobial resistance genes. J Antimicrob Chemother. 2012;67(11):2640-4.

68. Carattoli A, Zankari E, Garcia-Fernandez A, Voldby Larsen M, Lund O, Villa L, et al. In silico detection and typing of plasmids using PlasmidFinder and plasmid multilocus sequence typing. Antimicrob Agents Chemother. 2014; 58(7):3895-903

69. Darling AE, Mau B, Perna NT. ProgressiveMauve: multiple genome alignment with gene gain, loss and rearrangement. PLoS One. 2010;5: e11147.

70. Arndt D, Grant JR, Marcu A, Sajed T, Pon A, Liang Y, et al. PHASTER: a better, faster version of the PHAST phage search tool. Nucleic Acids Res. 2016; 44(W1):W16-21.

71. Bertelli C, Laird MR, Williams KP, Lau BY, Hoad G, Winsor GL, et al. IslandViewer 4: expanded prediction of genomic islands for larger-scale datasets. Nucleic Acids Res. 2017;45(W1):W30-W5.

72. Siguier P, Perochon J, Lestrade L, Mahillon J, Chandler M. ISfinder: the reference Centre for bacterial insertion sequences. Nucleic Acids Res. 2006; 34(Database issue):D32-6.

\section{Publisher's Note}

Springer Nature remains neutral with regard to jurisdictional claims in published maps and institutional affiliations. 